\title{
Conceptualising the Relationship Types and Attributes that Enable Stakeholders to Recruit SME Farmer Users into IS Design
}

\author{
Craig M. Parker \\ Deakin University \\ craig.parker@deakin.edu.au
}

Wahyudi Agustiono

University of Trunojoyo Madura

Rodney Carr

Deakin University

Dilal Saundage

Deakin University

\section{Abstract}

It can be difficult for organisations which develop an information system (IS) for use by many small and medium enterprises (SMEs) to recruit SME personnel during IS design. The paper addresses this problem by exploring the nature of relationships that organisational stakeholders can use to recruit SME personnel during IS design, which has received little attention in the literature. We present an interpretive, revelatory case study of the insights from managers and field officers who recruited SME farmers during the design of an interorganisational IS. We identified three relationship types, based on an existing framework in the literature derived from stakeholder theory: between managers of organisations; between managers and field officers; and between field officers and farmers. We extend this framework by incorporating relationship attributes based on social capital concepts: ties, shared cognition, structure, homophily and bridging capital. We found that the complex interplay of the three relationship types, and the degree of strength of the social capital attributes of these relationships, help explain how farmers were recruited into, or were discouraged from participating in, a lengthy IS design process.

Keywords: Small and medium enterprises, Farmers, Information systems design, Social capital, Stakeholder theory, User recruitment

\section{Introduction}

Most businesses in many economies are small and medium enterprises or SMEs (Cragg et al. 2011), which in our Australian context are defined as businesses with fewer than 200 staff (ABS 2015). Governments and other types of organisations develop information systems (IS) to support SMEs. For example, governments may develop decision support systems (DSS) to help farmers optimise land use (Miah et al. 2014), or develop websites which save SMEs time to access services and achieve compliance (Holgersson 2014). Organisations develop DSS for use by SMEs, including farmers, in developing countries in Africa (Doerflinger \& Dearden 2013; Oduor et al. 2018) and South East Asia (Noor \& Nordin 2012). These IS can fail due to a lack of SME adoption (Eastwood et al. 2017; Heeks 2008), which emphasises that it is important for the IS academic and practitioner communities to address this issue. 
A factor supporting IS adoption is SME involvement during IS design (Holgersson 2014), because it helps ensure an IS tool meets SME needs (Heeks 2008; Lynch \& Gregor 2004). The challenge, however, is that most SME owners are time poor and focus on their business (Cragg et al. 2011; Harwood 2011). In Australia, most SMEs are small firms with 19 or fewer staff (ABS 2015), and are independent decision-makers (Parker et al. 2015). Farmers in developing countries can distrust IS designers (Heeks 2008). This means IS designers can find it hard to recruit SMEs into an often long design process. Making matters worse, SMEs are heterogeneous (Parker et al. 2015), so that IS designers must recruit a diverse range of SMEs to increase the chances that disparate SMEs will adopt the IS (Holgersson 2014).

The problem we address in this paper is how organisations can capitalise on people who have existing, or can develop new, relationships with SME personnel to recruit them into IS design. A literature review by Parker et al. (2015) shows that research on SMEs and IS tends to focus on IS adoption and use, rather than IS design. We show in Section 2 that the few studies reporting on SME participation in IS design offer little insight into how SME personnel are recruited and by whom. The limited work on recruiting SME personnel in IS design suggests that recruitment is not trivial and that three relationship types help with recruitment, but offers little insight into these relationships: 1) recruiter relationships involve recruiters from organisations who use existing, or develop new, relationships with SME personnel to recruit the personnel; 2) enlister relationships are existing/new relationships between managers and recruiters, which enable recruiters to be enlisted into an IS design project; and 3) manager relationships are existing/new relationships among managers of organisations that lead to new organisations joining an IS design project, where these new organisations may employ or have access to potential recruiters.

We explore each relationship type via a revelatory and interpretive case study of how a government-led team recruited SME farmers when designing an inter-organisational IS that we call the Farm Planning Tool or FPT (pseudonym). We examined relationships among managers of organisations, some of whom had relationships with and enlisted field officers, which led to these field officers, who had relationships with farmers, to recruit farmers. We identified attributes of the relationship types that explained how managers involved new managers, how managers enlisted field officers, and how field officers recruited farmers. Relationship attributes are characteristics of a relationship, including the duration, and are traits of each member in the relationship that affects the relationship, such as the degree of similarity in knowledge/experience between the field officers and farmers. In this paper we thus address the research question: What attributes of relationships among managers, field officers and farmers help explain how farmers were recruited during FPT design?

The paper, in addressing this question, makes the following contributions. First, we fill a knowledge gap by presenting empirical evidence of how the three relationship types are interconnected, and enable managers and recruiters to recruit SME personnel into IS design. The few existing studies in this area only provide superficial insight. Second, we show that social capital concepts can help theorise the attributes of the three relationship types, and help explain how managers and recruiters can recruit farmers into IS design. Third, existing studies relating to SMEs and IS typically use social capital concepts to study IS adoption/use by SMEs, or IS design in an intra-organisational context. This paper instead provides empirical evidence that these concepts can also be used to theorise about recruiting SME personnel in IS design, which is prior to adoption/use, in an inter-organisational context. Fourth, we extend Boonstra's 
(2009) IS stakeholder management framework to address the neglected issue of how to recruit users during the IS design phases of an IS project by adding the three relationship types and their associated attributes based on social capital concepts. A practical contribution of the paper is to highlight the importance of the three relationship types and their associated attributes when recruiting users into IS design. IS design teams can use this insight to formulate strategies that can enable the emergence of desirable relationship types and attributes, and/or identify existing relationships with attributes most likely to recruit SME personnel. This is valuable because literature evidence confirms (e.g. Lynch \& Gregor 2004) that SME involvement in IS design can increase IS adoption.

The paper is structured as follows. Section 2 synthesises the limited literature which is relevant to the paper's research question. Section 3 summarises theoretical concepts relating to the three relationship types and their associated attributes. Section 4 summarises the revelatory case study and how the data was collected and analysed to address our research question. Section 5 uses concepts from Section 3 and presents evidence relating to the three relationship types, and associated attributes, that led to farmers being recruited. Section 6 discusses the paper's contributions. Section 7 concludes with the limitations, practical contributions and future research agenda arising from this study.

\section{Literature Review}

In this section we review empirical work that reports on designing an IS tool intended for use by many SMEs. Specifically, we review studies about existing/new relationships among stakeholders that led to SME personnel being recruited into IS design. We review studies in developed countries (e.g. Australia, USA and China) reporting on, for instance, the design of web portals for use by rural/regional SMEs (e.g. Fisher \& Craig 2005) and decision support systems (DSS) for farmers (e.g. Breuer et al. 2009; Cabrera et al. 2008; Huang et al. 2010; Jakku \& Thorburn 2010; Miah et al. 2014). We also review studies in developing countries, including Kenya (Gichamba \& Lukandu 2012; Oduor et al. 2018), Ethiopia (Zewge et al. 2014; 2015), Tanzania (Churi et al. 2013), South Africa (Doerflinger \& Dearden 2013; Merz et al. 2007), Tunisia (Ndou et al. 2011), Malaysia (Noor \& Nordin 2012), and Bangladesh (Islam \& Grönlund 2007). Studies in developing countries often report on the design of DSS for use by farmers, including mobile phone systems. We focus on studies where SME personnel were recruited to participate actively in, for instance, in-depth interviews, workshops and focus groups, because this can increase the success of IS adoption/use in developed countries (Holgersson 2014; Lynch \& Gregor 2004) and developing countries (Heeks 2008). Active methods imply that stakeholders need existing or new relationships with other stakeholders, and with SME personnel, to recruit SME personnel, and that the relationships will have attributes to support/hinder recruitment such as common norms and trust.

The literature suggests there are three broad relationship types among stakeholders, shown in Figure 1 and explained next, that enable the recruiting of SME personnel in one or more IS design stages. We review the literature that implies the importance of each type of relationship, and that certain attributes might enable one party in the relationship to recruit the other party. A relationship attribute, in the context of this paper, is a trait that can be compared between each party in a relationship, including degree of similarity in knowledge/ experience, or a characteristic of the relationship itself including duration. The attributes affect if or how one party can recruit the other via an existing or new relationship. We will give examples of the attributes that are evident in the literature in the sections that follow. 


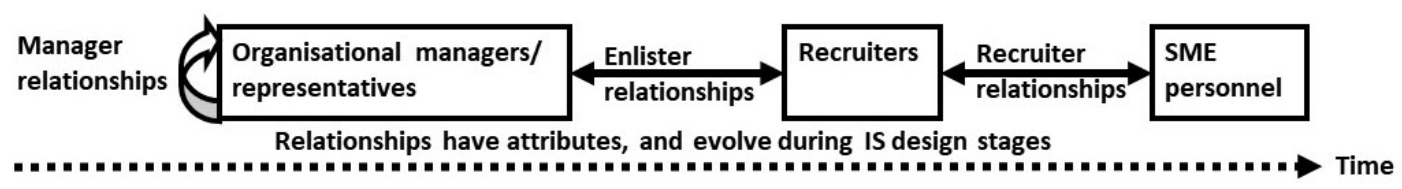

Figure 1: relationship types enabling SME recruitment into IS design stages

\subsection{Recruiter relationships: recruiters and SME personnel}

Recruiter relationships are where recruiters develop new, or use existing, relationships with SME personnel to recruit SMEs into IS design. This paper does not explore SME personnel who enlist other SME personnel, which has been found in the literature (e.g. Cerf et al. 2012; Zewge et al. 2014). Instead, we focus on recruiters, who are not SME personnel, and what relationships recruiters have or develop with SME personnel, because this is the first step so that, later on, any recruited SME personnel can enlist other SME personnel.

It was not clear in many studies who the recruiters were that recruited SMEs (Breuer et al. 2009; Cerf et al. 2012; Churi et al. 2013; Gichamba \& Lukandu 2012; Islam \& Grönlund 2007; Merz et al. 2007; Miah et al. 2014; Parker \& Sinclair 2001; Zewge et al. 2014; 2015). Fisher and Craig (2005), Salmivalli et al. (2008) and Tatnall and Burgess (2009) reported on failed IS projects and found that SMEs had little involvement in IS design, and did not state how representatives were recruited to steering committees nor whether the representatives were SMEs. Researchers coordinated some participatory methods (Cabrera et al. 2008; Huang et al. 2010; Ndou et al. 2011; Nolan et al. 2007; Noor \& Nordin 2012), but did not state if researchers such as doctoral students or employed research assistants, or other stakeholders such as staff of third-party organisations, were the ones who recruited SME personnel. Dans and Freire (2002) said two researchers had existing relationships with fishermen and fisher communities prior to designing an IS for use by fisheries and restaurants in Spain, but did not state if the researchers or other stakeholders were the ones who recruited SME personnel into the IS design project.

Only a few studies offer any insight into who were the recruiters, and what relationship attributes enabled recruiters to recruit SME personnel. One recruiter type is researchers. Oduor et al. (2018) and Jakku and Thorburn (2010) stated that they, as researchers, had prior relationships with farmers during an earlier project that helped them to recruit the same farmers into a new IS design project. Breuer et al. (2008), by contrast, stated they were given farmer contact details by other stakeholders, implying they had no relationships with farmers prior to recruitment. This implies that two recruiter relationship attributes were: 1) whether the relationship between recruiters and SME personnel existed prior to the IS design project, and 2) the duration or length of any pre-existing relationship. The limited studies to-date means it is unclear what impact these attributes have on recruitment.

These studies offer some limited insight into other possible relationship attributes. For example, Breuer et al. (2008, p. 389) said that recruiters were "... graduate students from a number of backgrounds including anthropology, agronomy, agricultural extension, natural resource management, forestry, geography, and community development". Breuer et al. did not state why this background was important, but it implies that such background is a relationship attribute that helped students recruit farmers because they would have common knowledge. Oduor et al. (2018) also did not explain the relationships that the researchers had with the secretariat (who were farmers) of the irrigation scheme in a Kenyan community. Oduor et al. said the research 
team included Kenyans and that the "... first author had lived in Kenya for a combined period of $\sim 25$ years... [and undertaken] research in user practices around water management and use in remote parts of arid and semi-arid Northern Kenya" (p. 4). Oduor et al. did not explain why this background was important, but it implies that researchers' local knowledge/experience was needed to recruit farmers. Oduor et al. emphasised the need for IS scholars to interact "... with farmers to understand internal politics, local dynamics, and historical changes..." (p. 8) to ensure IS designs help farmers. Breuer et al. and Oduor et al. thus imply that an important relationship attribute is common knowledge/experience between recruiters and SME personnel, because it helps ensure that recruiters understand the farmers' context. These studies suggest that if there is more common knowledge/experience, farmers are more likely to see the recruiters as credible and thus agree to participate in IS design. Oduor et al. also explained that the research team developed and maintained relationships with village elders, who can be farmers and can in turn espouse the team's credibility to other farmers. This suggests that a related relationship attribute may include ongoing trust with village elders, that must be developed over time, so that elders will in turn facilitate the recruiting of other farmers in their local community.

This is consistent with IS studies in developing countries which do not explicitly report on designing IS for farmers. For example, Heeks (2008) and Winschiers-Theophilus et al. (2012) emphasise that Western IS scholars must know local community cultures, because our knowledge/experiences, including technical know-how and no experience of poverty, reduces our credibility/trust with, and thus ability to recruit, farmers, etc. Further, Heeks and Winschiers-Theophilus et al. suggest that recruiting farmers would be essential because community members including farmers, rather than researchers, should drive IS design.

Recruiters can include other types of stakeholders, not just researchers and their students. For example, Doerflinger and Dearden (2013) outline a methodology for conducting IS design projects for communities in developing countries. The methodology involves buying agents from local organisations, and volunteers from foreign aid organisations, working as recruiters, because they have pre-existing and trusted relationships with SME personnel. This is consistent with the relationship attribute apparent between researchers and SMEs that we noted earlier. Doerflinger and Dearden's methodology does not, however, explain other relationship attributes that aid recruitment. For example, they do not explain the type of foreign aid work that local volunteers engage in, whether the volunteers are Westerners or from the same country, nor how long the relationships have existed between volunteers and SME personnel. These details are needed to understand the extent to which shared experience/ knowledge is needed by recruiters to convince SME personnel to participate.

In summary, our review suggests that recruiters can be researchers, students and volunteers from not-for-profit organisations, and that existing/new relationships between recruiters and SME personnel are needed to recruit SME personnel into IS design interviews, workshops, etc. The review emphasises, however, that there is limited insight into the relationship attributes which might explain the success or otherwise of the recruitment.

\subsection{Enlister relationships: between managers and recruiters}

Enlister relationships are where managers develop new or use existing relationships with recruiters. Managers use enlister relationships to identify, and enlist, recruiters who can then in turn recruit SME personnel via recruiter relationships. There is some evidence in the literature that enlister relationships are important but, similarly to recruiter relationships, the literature offers limited insight into the attributes of enlister relationships. 
The majority of studies cited in Section 2.1 do not provide evidence of enlister relationships because they do not clarify or provide information about how SMEs are recruited. Instead, the importance of enlister relationships, and attributes, is evident in the literature that explicitly indicates that recruiters were researchers (Breuer et al. 2008; Jakku \& Thorburn 2010; Oduor et al. 2018). For example, in Section 2.1 we said the Breuer et al. (2008) study involved graduate students being recruiters. This means the researchers must have enlisted students (i.e. enlister relationship), and students enacted the recruiter relationships with SME personnel. Breuer et al. did not clarify what teacher-student, or enlister, relationship attributes were needed, including if researchers made student involvement mandatory. We argue that such details may help explain the conditions that are needed to facilitate enlister relationships successfully. Similarly, Oduor et al. (2018) implied that enlister relationships were important because the authors, from IBM Research Africa, acknowledged that other work colleagues from IBM Research Africa were responsible for "... organizing the study logistics and facilitating continuous association with the participants" (p. 8). This suggests the authors had a managerial role in the project and enlisted colleagues, while the authors' colleagues were the recruiters. Oduor et al. imply a relationship attribute was the collegiality at IBM Research Africa that enabled Oduor et al., as managers, to enlist colleagues (i.e. enlister relationship), who then recruited farmers (i.e. recruiter relationship).

The methodology that Doerflinger and Dearden (2013) outline for conducting IS design projects for communities in developing countries also implies enlister relationships are important. For example, managers in foreign aid organisations, and perhaps other managerial stakeholders, would likely be the ones who enlisted volunteers who, as explained in Section 2.1, then became recruiters. Doerflinger and Dearden do not, however, clarify who enlisted the volunteers, nor the relationship attributes that the managers had with volunteers (i.e. enlister relationship) that leads to volunteers enacting recruiter relationships.

In summary, these examples suggest that understanding enlister relationships, and their attributes, may be important to help researchers and organisations determine how to enact enlister and recruiter relationships so that SME personnel can be recruited successfully. Our review highlights, however, that enlister relationships, and their attributes, have been largely overlooked in existing research into how to recruit SME personnel into IS design.

\subsection{Manager relationships: among organisational managers}

Manger relationships involve managers, or representatives, of organisations developing new or using existing relationships with managers/representatives of other organisations. These relationships involve negotiations and coordination that facilitate the enlister and recruiter relationships, and can include bringing in organisations with access to potential recruiters.

Most studies provided little or no insight into manager relationships. Some do not report on the relationships between researchers and managers of other organisations that facilitated enlister and recruiter relationships (Cerf et al. 2012; Churi et al. 2013; Gichamba \& Lukandu 2012; Huang et al. 2010; Jakku \& Thorburn 2010; Merz et al. 2007; Miah et al. 2014; Ndou et al. 2011; Noor \& Nordin 2012). Some studies stated the organisations involved, but not the roles each organisation had regarding direct or indirect SME recruitment (Dans \& Freire 2002; Islam \& Grönlund 2007; Merz et al. 2007; Oduor et al. 2018; Parker \& Sinclair 2001).

There was evidence in the literature that manager relationships and associated attributes are important, but some studies did not clarify how manager relationships led to enlister and/or 
recruiter relationships. For instance, some studies stated that organisational managers or representatives had existing, or developed new, relationships to form steering committees or consortia (Breuer et al. 2008; Breuer et al. 2009; Fisher \& Craig 2005; Salmivalli et al. 2008; Tatnall \& Burgess 2009). Of these studies, only Fisher and Craig (2005) and Salmivalli et al. (2008) outline the evolving political issues that affected the relationships among committee/ consortia members, and the effect on IS design, but they did not state if committee/consortia members had or developed relationships with recruiters (i.e. enlister relationships). This implied that manager relationship attributes include structure (e.g. committees), formality (e.g. contracts, funding), and power among managers of organisations. Nolan et al. (2007) stated how researchers developed relationships with managers of SME business networks by discussing the business case for a new IS to be used by SMEs, implying common interest was an important attribute in manager relationships. Cabrera et al. (2008) stated the researchers contacted government agencies to get the contact details of farmers, which implied that researchers had or developed relationships with agency managers. Zewge et al. (2015) said the researchers developed "official" relationships with managers in government agencies (i.e. manager relationships) as part of the research design. Nolan et al., Cabrera et al. and Zewge et al. offered no further, clear details about recruiting SME personnel that enabled us to determine how manager relationships led to enlister and recruiter relationships.

Doerflinger and Dearden (2013) state how manager relationships can lead to enlister and recruiter relationships. Their methodology for IS design in developing countries involves manager researchers developing relationships with local partner organisations that are formalised into contracts, while no contracts are used with local contacts including foreign aid organisations. This implies a manager relationship attribute is varying degrees of formality, which would then facilitate the enlister and recruiter relationships that are explained in the preceding sections. Nonetheless, they provide no further details of manager relationships to determine other attributes that enable these relationships to succeed.

In summary, these examples suggest that understanding manager relationships, and their attributes, may be important to help other IS scholars determine how to enact manager relationships, which then facilitate enlister and recruiter relationships. Our review suggests, however, that manager relationships, and their attributes, have been largely overlooked in prior research examining how to recruit SME personnel to participate actively in IS design.

Overall, we have shown there is little research that analyses in detail how the three relationship types, and associated attributes, can lead to recruiting SME personnel into an often lengthy IS design process. This is essential because empirical evidence in the literature shows that SME involvement can increase IS adoption by SMEs (e.g. Breuer et al. 2009; Doerflinger \& Dearden 2013; Lynch \& Gregor 2004). The next section examines the theoretical concepts that had potential to explain these relationship types and attributes.

\section{Theoretical background}

The literature cited in Section 2 does not use theories or concepts relevant to this paper's research question on the relationships among managers, recruiters and SME personnel, nor on the attributes that explain how the relationships lead to SME personnel being recruited into IS design. This is not surprising because we argued that most studies about designing IS for use by many SMEs do not examine these relationships, and associated attributes. 
We found Boonstra's (2009) IS stakeholder management framework, derived from stakeholder theory, to be a useful overarching framework for our study for three reasons. First, this framework identifies various stakeholder types involved in IS design projects, including project owners, project managers, developers and users. IS scholars often use stakeholder theory as an analytical framework to identify, analyse, categorise and prioritise stakeholder types in an IS project, including relations and tensions among stakeholder types (Pouloudi et al. 2016). In our study we focused on stakeholders who were managers in the manager and enlister relationships, and recruiters in the enlister and recruiter relationships.

The second reason Boonstra's framework was useful is because it categorises all stages of an IS project, where the two most relevant stages in this paper are the concept and development stages. The concept stage includes all activities prior to any programming that leads to a concept design, including eliciting user needs. The development stage involves using the concept design to create multiple prototype versions based on stakeholder evaluations. This latter stage ends when project leaders feel, in the case of prototyping, it specifies an IS enough to develop a fully-functional IS for deployment during an implementation stage. In our study we examined how the three relationship types, and associated attributes, can lead to many SME personnel being recruited into the concept and development stages. Many of the studies cited in Section 2 emphasise that SME personnel need to be involved in both stages to increase the chances that the resulting IS tool will be adopted by SMEs.

Third, Boonstra's framework specifies a continuum of stakeholder involvement ranging from passive, or being informed about the IS or consulted for opinions, to active involvement that increases in degree from influence on, or collaboration with other stakeholders, or to being responsible for one or more aspects of the IS. In our study we focused on how the three relationship types led to SME personnel being recruited in order to influence an IS design.

Addressing this paper's aim required theorising about the relationship attributes that help explain how the three relationship types contribute to SME personnel being recruited into an IS design project. We needed another theory to complement Boonstra's work, because the framework did not offer sufficient concepts to analyse the stakeholder relationships.

Social capital had the potential to complement Boonstra's framework because it posits that people can gain value or achieve their objectives via face-to-face and online social networks (Parker \& Castleman 2009). The objective for us was recruiting SMEs via the relationship types. Social capital supports analysing a social system to identify actors who have relationships, which is a process consistent with our goal of examining relationships. Table 1 summarises the interrelated social capital concepts. Actor network theory (Tatnall \& Burgess 2009) and stakeholder theory (Pouloudi et al. 2016) posit that stakeholder relations can be based on power, but this attribute is part of the strength of ties in social capital.

The concepts from social capital appeared to suggest attributes of relationships that might facilitate SME personnel being recruited into IS design. Our review in Section 2 provided some initial support for our conclusion. For example, structure had potential to theorise if recruiters have prior relationships with SME personnel (i.e. recruiter relationships), managers have a working relationship with recruiters (i.e. enlister relationships), and managers have existing or need to develop new relationships with managers of other organisations (i.e. manager relationships). Ties had the potential to theorise the duration of prior relationships, the trust that can develop over time in the three relationship types and, in the case of manager relationships, the degree of formality such as the use of contracts. Homophily had the potential 
to theorise the degree of common knowledge/experience among those in all three relationship types. Shared cognition had the potential to make sense of why the three relationship types can be difficult to develop, including when IS researchers have different worldviews to farmers in developing countries. Despite the potential of these social capital concepts, the limited research into the three relationship types meant further in-depth research was needed to examine if these attributes explained how relationships among stakeholders helped recruit SME personnel into IS design.

\begin{tabular}{|l|l|}
\hline \multicolumn{1}{|c|}{ Attribute } & \multicolumn{1}{c|}{ Concept/attribute description } \\
\hline Ties & $\begin{array}{l}\text { Stronger ties Nahapiet and Ghoshal (1998) call it 'relational dimension') involve actors } \\
\text { having interpersonal, direct relations characterised, for instance, by reciprocity, long } \\
\text { duration, frequency, trust, shared obligations and power. For instance, families have very } \\
\text { strong ties. Weaker ties involve low intimacy, trust, duration, etc, and absent ties involve } \\
\text { no direct actor relations (Granovetter 1973). }\end{array}$ \\
\hline Structure & $\begin{array}{l}\text { The extent/number, or patterns, of connections in a social network which enable an actor to } \\
\text { be reached by, and to reach other, actors. Structural holes can occur where many actors in } \\
\text { the social network are disconnected from, or have no/weak ties to, other actors in the same } \\
\text { network (Nahapiet \& Ghoshal 1998). }\end{array}$ \\
\hline Shared cognition & $\begin{array}{l}\text { The degree to which actors in a social network share, for instance, common language, } \\
\text { codes, narratives, interests and values (Nahapiet \& Ghoshal 1998). }\end{array}$ \\
\hline $\begin{array}{l}\text { Homophily- } \\
\text { heterophily }\end{array}$ & $\begin{array}{l}\text { A continuum from people being homophilous (e.g. common behaviour, practices, status, } \\
\text { demographics, etc) and forming stronger ties at higher rates, relative to the other extreme: } \\
\text { very dissimilar or heterophilous (McPherson et al. 2001). }\end{array}$ \\
\hline Bridging capital & $\begin{array}{l}\text { The degree to which resources can be brought into existing relationships from external } \\
\text { social networks (Putnam 2000). This is affected by structural holes when actors in a social } \\
\text { network are disconnected from, or have no/weak ties to, actors in external networks } \\
\text { (Nahapiet \& Ghoshal 1998). }\end{array}$ \\
\hline
\end{tabular}

Table 1: Social capital concepts (attributes of the relationship types)

\section{Research approach}

We needed a research approach for examining the design of an IS intended for use by SMEs so that we could explore in detail the relationships that enabled managers and recruiters to recruit SMEs. Relationships, and associated attributes, are subjective and depend on sociohistorical contexts, which implied a qualitative and interpretive approach was best (Walsham 1995). Yin (2014) explains that a single case is suitable when the study is revelatory in nature, which applied here due to the limited research into how the three relationship types, and associated attributes, lead to SME personnel being recruited into IS design. We had access to a revelatory case study where SME farmers were recruited into the concept and development stages of an inter-organisational, web-based IS called the Farm Planning Tool (FPT, pseudonym). Field officers from a government agency and a private organisation had worked closely with farmers prior to the project, and recruited farmers into the FPT design. The next sections introduce the case study, and the data collection and analysis approach, which helped us address the question: What attributes of relationships among managers, field officers and farmers help explain how farmers were recruited during FPT design?

\subsection{Overview of the revelatory case study}

The case study that addressed the research question related to the design, from 2005 to 2007, of the FPT for farmers. The FPT was an inter-organisational web-based IS with aerial, salinity 
and other maps that farmers could use to monitor and manage farm activity and reduce environmental impact. The organisations involved during the project were:

- $\quad$ The Department of Environment (abbreviated to DeptEnv) was a government agency in an Australian state or province, which protected public land such as parklands and forests from ecological damage, including from activities by adjacent private farms. The DeptEnv provided funding for the FPT design project.

- Four State Catchment Authorities (SCA1, SCA2, SCA3, SCA4), which were Australian state government agencies each charged with protecting public waterways such as rivers, including fertiliser run-off from farms, in different regions in the state. The SCAs ran the project.

- $\quad$ The Department of Land (DeptLand), which was a government agency charged with improving farming practices to achieve higher productivity, including initiatives relating reducing ecological damage by farmers if there was a link to productivity.

- $\quad$ SpatialCo, which ran design workshops and developed the FPT prototype.

- $\quad$ DairyCo, which was a cooperative of independent dairy farmers, and became a new member of the project team in later stages of the FPT design.

Prior to the start of the FPT project, government restructures meant DeptEnv and DeptLand and their field officers could no longer help farmers with reducing environmental impact. They therefore were not formally involved in the FPT design project, but continued to be involved indirectly. DeptEnv, as noted above, provided funding for most FPT design stages.

The government agencies aimed to offer farmers with help, such as developing software like the FPT, to reduce their environmental impact by better managing farming activity such as fertiliser use, nutrient loss and effluent management. This was critical because there were over 35,000 farms in the state at the time, all potentially causing ecological damage. The agencies employed their own field officers, or extension officers, to work with farmers.

The impetus for designing the web-based FPT was that an earlier project, where farmers used paper worksheets to plan reduced environmental impacts of farms, did not meet the needs of farmers, nor the needs of agencies wanting to aggregate information to report against government targets. The FPT project team knew it was critical to involve farmers actively during the design because, at the time, web-based spatial tools (e.g. Google Maps), were new and unknown to most farmers. The team selected farmers interested in reducing their environmental impact, and more likely to participate in months of FPT design cycles.

In addition to developing an IS to help farmers manage farm activities, the project team needed the FPT to be designed so that agencies could access information entered by farmers, and to aggregate that information to monitor and report on progress toward government targets on reducing environmental impacts. The FPT was thus an inter-organisational IS involving bidirectional information sharing between farmers and agencies. Also, the field officers of each agency needed the FPT to be designed so they could use it to encourage farmers to implement farming practices which aligned with government targets.

Table 2 summarises the three types of intended users of the FPT and their basic needs. 


\begin{tabular}{|l|l|l|}
\hline \multicolumn{1}{|c|}{ User types } & \multicolumn{1}{|c|}{ Information inputs } & \multicolumn{1}{c|}{ Information outputs } \\
\hline $\begin{array}{l}\text { Government } \\
\text { managers }\end{array}$ & $\begin{array}{l}\text { Specify targets to reduce environmental } \\
\text { impact, conditions of natural resources, } \\
\text { provide recent spatial maps for use by } \\
\text { farmers. }\end{array}$ & $\begin{array}{l}\text { Aggregate farm data for reports and planning at } \\
\text { all state and catchment/regional levels. }\end{array}$ \\
\hline Field officers & $\begin{array}{l}\text { Review and approve farmer action plans. } \\
\text { Entry of farm details on behalf of farmers } \\
\text { if required. }\end{array}$ & $\begin{array}{l}\text { Aggregate farm data, develop summary reports } \\
\text { on activities undertaken (e.g. farms visited, } \\
\text { outcomes reviewed, activities for follow up), } \\
\text { create maps to assist with planning/activities. }\end{array}$ \\
\hline & $\begin{array}{l}\text { Input farm data including paddock } \\
\text { details (e.g. layout), details on initiatives } \\
\text { to reduce environmental impact (e.g. } \\
\text { action plans, targets, proposed activities, } \\
\text { support requests, locations with issues). }\end{array}$ & $\begin{array}{l}\text { Produce farm paddock map, report on actives } \\
\text { (e.g. fertiliser inputs, progress on targets } \\
\text { benchmark against other farms, measurements } \\
\text { (e.g. fencing). }\end{array}$ \\
\hline
\end{tabular}

Table 2: Intended FPT users and information inputs/outputs

The project involved over 50 farmers during various design stages, but with challenges. For instance, most farms in Australia are small, defined as land area of 500 hectares or less (ABS 2012), rather than defined by staff numbers, and most farmers in the FPT project had farms under 1000 hectares. The exact farm sizes for participants are unknown. Farms have typical SME traits, including farmers being time poor, having decision-making power (ABS 2012), and farms being heterogeneous in terms of IS expertise, crops, livestock (e.g. dairy, beef and mixed crop farms), sizes ranging from a few to 1000 hectares, hobby farms or commercial farms, and farmer gender/age (ABS 2012). The FPT team succeeded in recruiting and involving diverse farmers in IS design over many months, as explained further in Section 4.2.

The FPT team claimed the project was successful on three grounds. First, 1,350 farmers from eight SCA regions had FPT accounts by August 2009. Of these farmers, 832 used the FPT to record basic property details and boundaries, and 696 created paddock boundaries. This was despite the FPT still being a prototype because it was not released, was promoted mainly via word-of-mouth, and was only a proof-of-concept. Second, the FPT team reported that, overall, farmers found the FPT usable and useful based on evaluations involving interviews and surveys of farmers who were involved during the design. Third, the proof-of-concept achieved by the FPT project was used as input into a new project to develop standards, which thirdparty IS vendors can use to exchange spatial and farming data with agency maps.

\subsection{Data collection and analysis}

The data collection and analysis used to answer the research question in this paper was part of a larger study conducted from June 2012 to December 2013. We used the framework by Boonstra (2009), summarised in Section 3, to identify managers and recruiters who recruited farmers into the concept and development stages of FPT design. A hermeneutic process was used to collect and analyse interviewee recollections (Klein \& Myers 1999). The managers and recruiters we interviewed were identified using snowballing by asking each interviewee who else to contact, because it was not known prior to data collection who recruited farmers and how. Heckathorn (2011) states that snowballing is a suitable method to study social network construction. This aligned with our aim of studying the recollections of managers and recruiters about whether and how they recruited farmers. For example, using this method it was determined that: 
- $\quad$ Field officers were the main recruiters who recruited farmers during the concept and development stages of the FPT project;

- SpatialCo was the IS vendor during both stages, and individual SpatialCo staff ran workshops with farmers, but they were not involved in recruiting farmers;

- $\quad$ DeptLand managers initially helped during the project, but later encouraged its field officers to recruit farmers to use an alternative tool to the FPT prototype; and

- $\quad$ DairyCo managers joined the FPT project during the development stage. DairyCo field officers, or recruiters, were the ones who recruited dairy farmers during an evaluation of the FPT prototype.

We continued the snowballing approach until we identified all organisational managers and recruiters who were available to participate in the study. Table 3 lists the interviewees, their main roles during FPT design (and explained further in Section 5), and the insights they provided. The underlined text in Table 3 identifies recruiters who recruited farmers directly during one or more stages of the FPT design. These interviewees gave access to over 200 documents, including evaluation reports and design documents.

\begin{tabular}{|c|c|}
\hline Interviewees & FPT design roles and insights provided \\
\hline $\begin{array}{l}\text { Project-Manager- } \\
\text { SCA1 }\end{array}$ & $\begin{array}{l}\text { Represented one SCA (i.e. SCA1) on the steering committee; managed the FPT design } \\
\text { project; directly recruited some farmers; and had first-hand experience of the project } \\
\text { history, stakeholder roles, and how farmers were recruited during the FPT design. }\end{array}$ \\
\hline SpatialCo-Manager & $\begin{array}{l}\text { SpatialCo was commissioned to develop the FPT prototype; ran all design workshops } \\
\text { with farmers; developed FPT specification documents; improved the FPT using farmer } \\
\text { feedback; and had first-hand experience of the project history, and how farmers were } \\
\text { recruited during the FPT design. }\end{array}$ \\
\hline $\begin{array}{l}\text { DeptLand- } \\
\text { Researcher }\end{array}$ & $\begin{array}{l}\text { Represented a government agency on the steering committee; participated in all FPT } \\
\text { design stages; and had a key role in designing the FPT prototype evaluation activities } \\
\text { involving SME farmers. }\end{array}$ \\
\hline DeptLand-Manager & $\begin{array}{l}\text { Provided background details on the FPT project and issues during the design stages } \\
\text { which impacted on recruiting farmers. }\end{array}$ \\
\hline DeptLand-Fellow & Provided technical background of the FPT and the design stages. \\
\hline Field-Officer-SCA2 & $\begin{array}{l}\text { Provided first-hand recollections of how she and other SCA field officers recruited } \\
\text { farmers; provided training and support for farmers during the FPT design; and created } \\
\text { spreadsheet tools for farmers which complemented the FPT prototype. }\end{array}$ \\
\hline $\begin{array}{l}\text { DeptLand-Field- } \\
\text { Officer1 and } \\
\text { DeptLand-Field- } \\
\text { Officer2 }\end{array}$ & $\begin{array}{l}\text { Supported farmers with farm planning and using software; and provided first-hand } \\
\text { recollections of tensions affecting involving farmers during FPT design. DeptLand- } \\
\text { Field-Officer1 was initially a project officer and provided FPT training for farmers } \\
\text { during the FPT design until tensions emerged. }\end{array}$ \\
\hline DairyCo-Manager & $\begin{array}{l}\text { Represented DairyCo in the FPT design consortium and steering committee, and gave } \\
\text { details of how farmers were recruited during FPT design. }\end{array}$ \\
\hline $\begin{array}{l}\text { DairyCo-Field- } \\
\text { Officer1 and } \\
\text { DairyCo-Field- } \\
\text { Officer2 }\end{array}$ & $\begin{array}{l}\text { Provided first-hand recollections of how DairyCo field officers recruited dairy farmers; } \\
\text { provided FPT training to farmers; and supported farmers with various dairy-related } \\
\text { farm management activities (e.g. compliance). }\end{array}$ \\
\hline
\end{tabular}

Table 3: Interviewees, FPT design roles and insights provided

The recollections of managers and recruiters were elicited using semi-structured interviews to give interviewees the flexibility to provide recollections in their own words (Kvale 2007) about recruiting farmers during FPT design. The interviews were audio-taped and transcribed. Questions started broadly, including asking about their role during FPT design and how the 
project started, and then asked the interviewees to describe the design steps involving SMEs. This helped align the steps with Boonstra's two design stages. The questions then focused on when and how the managers and recruiters influenced how farmers were recruited, and if they got other recruiters to invite farmers. We asked managers about the challenges they had with enlisting recruiters, and field officers about the challenges with recruiting farmers. We asked the interviewees how they handled these challenges.

Table 4 summarises the FPT design steps during the concept and development stages in which farmers were involved, the duration of farmer involvement during the steps, the main organisations involved, and the field officers who recruited farmers. The table shows that many farmers invested a lot of time by taking part in workshops and evaluations over months. Table 4 implies that participation numbers decreased as time commitments increased, which emphasised the important role of recruiter relationships, between field officers and farmers, in supporting farmer participation.

\begin{tabular}{|c|c|c|c|c|c|c|}
\hline Stage & Pre-IS design & Both stages & Concept & Concept & Development & Developmen \\
\hline Step & $\begin{array}{l}\text { Pre-FPT } \\
\text { project } \\
\text { (paper-based) }\end{array}$ & $\begin{array}{l}\text { FPT reference } \\
\text { group formed }\end{array}$ & $\begin{array}{l}\text { FPT concept } \\
\text { design } \\
\text { workshops }\end{array}$ & $\begin{array}{l}\text { FPT mock- } \\
\text { up } \\
\text { workshops }\end{array}$ & $\begin{array}{l}\text { FPT prototype } \\
\text { evaluation } 1\end{array}$ & $\begin{array}{l}\text { FPT } \\
\text { prototype } \\
\text { evaluation } 2\end{array}$ \\
\hline $\begin{array}{l}\text { Funding } \\
\text { entities }\end{array}$ & $\begin{array}{l}\text { Federal Govt } \\
\text { gave funding. }\end{array}$ & $\begin{array}{l}\text { DeptEnv gave } \\
\text { funding. }\end{array}$ & $\begin{array}{l}\text { DeptEnv } \\
\text { gave } \\
\text { funding. }\end{array}$ & $\begin{array}{l}\text { DeptEnv } \\
\text { gave } \\
\text { funding. }\end{array}$ & $\begin{array}{l}\text { DeptEnv gave } \\
\text { funding. }\end{array}$ & $\begin{array}{l}\text { DairyCo used } \\
\text { its govt. } \\
\text { funding. }\end{array}$ \\
\hline $\begin{array}{c}\text { Main } \\
\text { agencies/ } \\
\text { companies } \\
\text { involved }\end{array}$ & $\begin{array}{l}\text { DeptEnv, } \\
\text { SCA1, SCA2, } \\
\text { SCA5 }{ }^{*}, \text { FA* }^{*} \\
\text { DeptLand }\end{array}$ & $\begin{array}{l}\text { SCA1, SCA2, } \\
\text { SCA3, } \\
\text { SpatialCo }\end{array}$ & $\begin{array}{l}\text { SCA1, SCA2, } \\
\text { SCA3, } \\
\text { SpatialCo }\end{array}$ & $\begin{array}{l}\text { SCA1, SCA2, } \\
\text { SCA3, } \\
\text { SpatialCo }\end{array}$ & $\begin{array}{l}\text { SCA1, SCA2, } \\
\text { SCA3, SCA4, } \\
\text { SpatialCo }\end{array}$ & $\begin{array}{l}\text { DairyCo, } \\
\text { SpatialCo }\end{array}$ \\
\hline $\begin{array}{c}\text { Key } \\
\text { issues/ } \\
\text { activities }\end{array}$ & $\begin{array}{l}\text { Farmers used } \\
\text { paper } \\
\text { booklets/ } \\
\text { worksheets to } \\
\text { manage } \\
\text { environmental } \\
\text { impact. } \\
\text { Farmers } \\
\text { found this } \\
\text { complex \& } \\
\text { time- } \\
\text { consuming. } \\
\text { Agencies } \\
\text { found farmer } \\
\text { data was not } \\
\text { useful for } \\
\text { monitoring } \\
\text { targets. The } \\
\text { FPT was } \\
\text { intended to } \\
\text { solve the } \\
\text { issues. }\end{array}$ & $\begin{array}{l}\text { DeptEnv \& } \\
\text { DeptLand left } \\
\text { because state } \\
\text { govt. } \\
\text { restructure } \\
\text { meant they } \\
\text { could not help } \\
\text { farmers with } \\
\text { environmental } \\
\text { impact. SCAs } \\
\text { took over } \\
\text { project. } \\
\text { Reference } \\
\text { group farmers } \\
\text { gave input so } \\
\text { high-level } \\
\text { concept } \\
\text { design of the } \\
\text { FPT would } \\
\text { cater for } \\
\text { farmer needs. }\end{array}$ & $\begin{array}{l}\text { High-level } \\
\text { design was } \\
\text { presented to } \\
\text { farmers } \\
\text { during local } \\
\text { workshops } \\
\text { arranged by } \\
\text { SCA field } \\
\text { officers. } \\
\text { SpatialCo } \\
\text { ran the } \\
\text { workshops } \\
\text { to show } \\
\text { concept } \\
\text { design, \& } \\
\text { farmers gave } \\
\text { input. This } \\
\text { input was } \\
\text { used to } \\
\text { create mock- } \\
\text { up screens of } \\
\text { FPT design. }\end{array}$ & $\begin{array}{l}\text { Farmers } \\
\text { took part in } \\
\text { workshops } \\
\text { arranged by } \\
\text { SCA field } \\
\text { officers. } \\
\text { SpatialCo } \\
\text { showed the } \\
\text { mock-up to } \\
\text { show how it } \\
\text { might work, } \\
\text { \& sought } \\
\text { farmer input } \\
\text { to help. This } \\
\text { input was } \\
\text { used to } \\
\text { create a } \\
\text { detailed FPT } \\
\text { prototype } \\
\text { specification. }\end{array}$ & $\begin{array}{l}\text { DeptLand } \\
\text { tried to stop } \\
\text { farmer } \\
\text { involvement } \\
\text { by } \\
\text { encouraging } \\
\text { use instead of } \\
\text { their own } \\
\text { desktop } \\
\text { mapping IS. } \\
\text { SCA field } \\
\text { officers } \\
\text { trained/ } \\
\text { supported } \\
\text { farmers to use } \\
\text { the FPT. } \\
\text { Farmers } \\
\text { joined } \\
\text { workshops, } \\
\text { interviews \& } \\
\text { surveys to } \\
\text { evaluate FPT. }\end{array}$ & $\begin{array}{l}\text { No DeptEnv } \\
\text { funding; no } \\
\text { SCA field } \\
\text { officer time to } \\
\text { support more } \\
\text { farmers. } \\
\text { DeptLand put } \\
\text { DairyCo in } \\
\text { contact with } \\
\text { FPT team. } \\
\text { DairyCo } \\
\text { funded } \\
\text { changes they } \\
\text { needed. } \\
\text { Evaluation } \\
\text { same as first } \\
\text { but longer } \\
\text { period \& field } \\
\text { officer } \\
\text { support from } \\
\text { DairyCo. }\end{array}$ \\
\hline Recruiters & $\begin{array}{l}3 \text { SCA field } \\
\text { officers kept } \\
104 \text { farmers } \\
\text { involved. }\end{array}$ & $\begin{array}{l}\text { Project- } \\
\text { Manager- } \\
\text { SCA1 kept } 3 \\
\text { farmers } \\
\text { involved. }\end{array}$ & $\begin{array}{l}\text { SCA field } \\
\text { officers } \\
\text { (farmer data } \\
\text { not } \\
\text { available). }\end{array}$ & $\begin{array}{l}\text { SCA field } \\
\text { officers } \\
\text { (farmer } \\
\text { numbers not } \\
\text { available). }\end{array}$ & $\begin{array}{l}5 \text { SCA field } \\
\text { officers kept } \\
46 \text { farmers } \\
\text { involved. }\end{array}$ & $\begin{array}{l}\text { DairyCo field } \\
\text { officers kept } \\
18 \text { farmers } \\
\text { involved. }\end{array}$ \\
\hline
\end{tabular}




\begin{tabular}{|c|c|c|c|c|c|c|}
\hline Stage & Pre-IS design & Both stages & Concept & Concept & Development & Development \\
\hline $\begin{array}{c}\text { SME } \\
\text { diversity }\end{array}$ & $\begin{array}{l}\text { Many } \\
\text { livestock/ crop } \\
\text { \& size farms }\end{array}$ & Not diverse. & \multicolumn{3}{|c|}{$\begin{array}{l}\text { Many livestock/crop farms; farm sizes; owner } \\
\text { ages, gender \& IS skills; hobby vs commercial } \\
\text { farms. }\end{array}$} & $\begin{array}{l}\text { Dairy } \\
\text { farmers. }\end{array}$ \\
\hline $\begin{array}{c}\text { SME } \\
\text { involve- } \\
\text { ment } \\
\text { duration }\end{array}$ & $\begin{array}{l}\text { Over } 12 \\
\text { months (SCA1 } \\
-38, \text { SCA2 - } \\
34, \text { SCA5 }^{*}- \\
32) .\end{array}$ & $\begin{array}{l}\text { Entire FPT } \\
\text { design project. }\end{array}$ & $\begin{array}{l}\text { One } \\
\text { workshop } \\
\text { (farmer data } \\
\text { not } \\
\text { available). }\end{array}$ & $\begin{array}{l}\text { Same } \\
\text { farmers as } \\
\text { prior } \\
\text { workshop } \\
\text { (farmer data } \\
\text { not } \\
\text { available). }\end{array}$ & $\begin{array}{l}4 \text { months } \\
\text { (SCA1 - 10, } \\
\text { SCA2 - 14, } \\
\text { SCA3 - 6, } \\
\text { SCA4 - 16) }\end{array}$ & $\begin{array}{l}18 \text { months. } 18 \\
\text { dairy farmers } \\
\text { in SCA4 } \\
\text { region. }\end{array}$ \\
\hline
\end{tabular}

Table 4: Summary of FPT design stages and the involvement of farmers

Wolcott's (1994) description, analysis and interpretation approach was applied to transform the qualitative data into a credible case narrative. Analysis and interpretation involved hermeneutic cycles based on the Klein and Myers (1999) set of principles of interpretive field research. Each cycle involved (re-)reading documents and interview transcripts, and coding (sub-)nodes on the chronological processes of the project. A case narrative, or description, was then written, which satisfied the principle of 'contextualisation' (Klein \& Myers 1999), by including the socio-historical context of the FPT design. The writing process led to further cycles of analysis and interpretation. The principle of 'multiple interpretations' (Klein \& Myers 1999) was satisfied by using hermeneutic cycles of triangulation to mitigate issues with interviewees recalling project details after 5-6 years (Patton 2002). This involved comparing their recollections with one another and with FPT project documents.

The social capital concepts in Section 3, which we used in this paper to make sense of the findings, were identified retrospectively during the hermeneutic cycles of data analysis. This is consistent with other IS research, including Bødker et al. (2014) and Schlichter and Rose (2013). The emergent themes about the three relationship types, and the concepts to make sense of the relationship attributes, thus co-evolved with the data analysis. Each relationship type became a theme in our analysis, and the relationship attributes were sub-themes.

\section{Findings}

Figure 2 shows how the three relationship types from Section 2, each in a different colour, evolved from the pre-FPT design stage, to the concept and development stages of the FPT design. Figure 2 summarises how recruiters were SCA and DairyCo field officers, and ProjectManager-SCA1 from the project management group (i.e. recruiter relationships). DeptLand field officers also had relationships with farmers, but these field officers impeded farmer recruitment during the development stage. Figure 2 shows that it was SCA, DairyCo and DeptLand representatives or managers who enlisted field officers (i.e. enlister relationships) to facilitate recruiter relationships. Finally, Figure 2 shows that manager relationships among the SCAs, DeptEnv, DeptLand, SpatialCo and DairyCo evolved throughout the FPT design project. Manager relationships thus contextualised how the enlister and recruiter relationships evolved, and the effect on farmer recruitment. In the following sections we explain the findings for each relationship type in more detail.

We use the Table 1 attributes, based on social capital concepts, to explain how the three relationship types influenced farmer recruitment in the FPT design project. Table 5 summarises the attribute levels which emerged from our hermeneutic analysis of the findings. 
We state 'extrapolated' when the description of a level was not observed in the findings, but are extrapolated based on other levels which were evident in the findings. The levels varied during IS design, and among instances of each relationship type, so that each relationship type can appear in multiple cells in Table 5. We use italics in each section below to show how the social capital concepts apply, as used in other IS studies (e.g. Lyytinen \& Damsgaard 2011; Rodon et al. 2008).

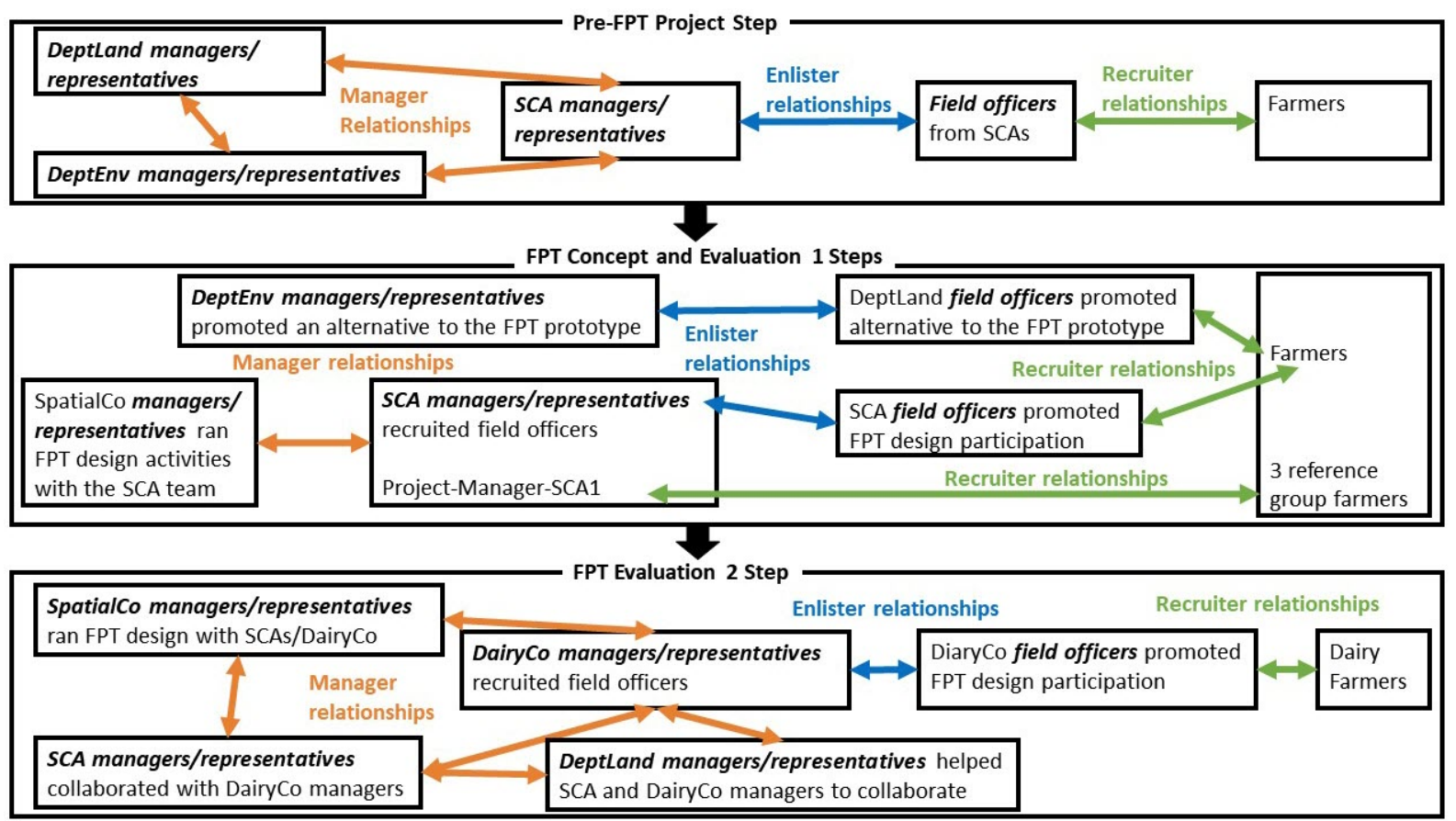

Figure 2: Evolving relationship types during FPT design to recruit farmers

\begin{tabular}{|c|c|c|c|c|c|}
\hline Levels & Ties & Shared cognition & Homophily & Structure & $\begin{array}{c}\text { Bridging } \\
\text { capital } \\
\end{array}$ \\
\hline Weak & $\begin{array}{l}\text { No power/trust. Short } \\
\text { duration/ infrequent. } \\
\text { Temporary shared } \\
\text { obligation/reciprocity } \\
\text { prior to IS design (RR, } \\
\text { ER, MR). }\end{array}$ & $\begin{array}{l}\text { Some general } \\
\text { shared language, } \\
\text { narratives and } \\
\text { values. Can align } \\
\text { to the IS design } \\
\text { (RR, MR). }\end{array}$ & $\begin{array}{l}\text { Some similar } \\
\text { practices/ } \\
\text { behaviour due to } \\
\text { collaborative roles. } \\
\text { Can align to the IS } \\
\text { design (RR). }\end{array}$ & $\begin{array}{l}\text { Few direct } \\
\text { links prior } \\
\text { to IS } \\
\text { design } \\
\text { (MR). }\end{array}$ & $\begin{array}{l}\text { Few external } \\
\text { resources to } \\
\text { support the } \\
\text { relationship } \\
\text { type } \\
\text { (extrapolated). }\end{array}$ \\
\hline Medium & $\begin{array}{l}\text { Medium frequency/ } \\
\text { duration. Maybe } \\
\text { shared obligation/ } \\
\text { reciprocity/trust } \\
\text { development prior to } \\
\text { IS design (RR, ER, } \\
\text { MR). }\end{array}$ & $\begin{array}{l}\text { Some specific } \\
\text { shared language, } \\
\text { narratives and } \\
\text { values. Can align } \\
\text { to the IS design } \\
\text { (RR, MR). }\end{array}$ & $\begin{array}{l}\text { Many similar } \\
\text { practices/ } \\
\text { behaviour due to } \\
\text { collaborative roles. } \\
\text { Can align to the IS } \\
\text { design (RR, ER). }\end{array}$ & $\begin{array}{l}\text { Some } \\
\text { direct links } \\
\text { prior to IS } \\
\text { design } \\
\text { (extrapol- } \\
\text { ated). }\end{array}$ & $\begin{array}{l}\text { Some external } \\
\text { resources to } \\
\text { support the } \\
\text { relationship } \\
\text { type (RR, MR). }\end{array}$ \\
\hline High & $\begin{array}{l}\text { Trust, long duration/ } \\
\text { high frequency. Maybe } \\
\text { some shared } \\
\text { obligation/ } \\
\text { reciprocity/power } \\
\text { prior to IS design (RR, } \\
\text { ER). }\end{array}$ & $\begin{array}{l}\text { Many specific } \\
\text { shared language, } \\
\text { narratives and } \\
\text { values. Can align } \\
\text { to the IS design } \\
\text { (RR, ER). }\end{array}$ & $\begin{array}{l}\text { Very similar } \\
\text { roles/practices/ } \\
\text { behaviour in } \\
\text { different contexts. } \\
\text { Can align to the IS } \\
\text { design (MR). }\end{array}$ & $\begin{array}{l}\text { Many } \\
\text { direct links } \\
\text { prior to IS } \\
\text { design } \\
\text { (RR, ER, } \\
\text { MR). }\end{array}$ & $\begin{array}{l}\text { Many external } \\
\text { resources to } \\
\text { support the } \\
\text { relationship } \\
\text { type (MR). }\end{array}$ \\
\hline
\end{tabular}

Table 5: Attribute levels emerging from the datalevident in the relationship types 


\subsection{Manager relationships: manager relationships with other managers}

Table 4 shows that the involvement by the SCAs, SpatialCo, DeptEnv, DeptLand and DairyCo evolved during paper-based pre-FPT project, and concept and development stages of the FPT project. Table 6 summarises the manager relationship attributes, which shows how relations among managers and representatives of these organisations evolved. We explain each of the three key evolutionary stages in Table 6, and their associated attributes, separately next.

\begin{tabular}{|l|l|l|l|}
\hline \multicolumn{1}{|c|}{ Attribute } & $\begin{array}{c}\text { Paper-based pre-FPT } \\
\text { project stage }\end{array}$ & $\begin{array}{c}\text { Concept stage and FPT } \\
\text { evaluation step 1 (development } \\
\text { stage) }\end{array}$ & $\begin{array}{l}\text { FPT evaluation step 2 } \\
\text { (development stage) }\end{array}$ \\
\hline Structure & $\begin{array}{l}\text { High with SCA, } \\
\text { DeptEnv, DeptLand } \\
\text { managers due to all } \\
\text { attending meetings. }\end{array}$ & $\begin{array}{l}\text { Weak with SCA, DeptEnv, } \\
\text { DeptLand after restructure. High } \\
\text { with SCA, SpatialCo managers } \\
\text { (attended meetings) }\end{array}$ & $\begin{array}{l}\text { High with SCA, } \\
\text { SpatialCo, DairyCo } \\
\text { managers due to all } \\
\text { attending meetings. }\end{array}$ \\
\hline Ties & Weak & $\begin{array}{l}\text { Weak with SCA, DeptEnv, } \\
\text { DeptLand managers. Medium } \\
\text { with SCA, SpatialCo manager. }\end{array}$ & Weak \\
\hline Shared cognition & Medium & $\begin{array}{l}\text { Weak with SCA, DeptEnv, } \\
\text { DeptLand managers. Medium } \\
\text { with SCA, SpatialCo managers. }\end{array}$ & Medium \\
\hline Homophily & High & High & High \\
\hline Bridging capital & Medium & Medium & High \\
\hline
\end{tabular}

Table 6: Evolution of manager relationships and associated attributes

DeptEnv, DeptLand and each SCA had managers/representatives with direct relationships at consortium meetings (high structure) for the paper-based pre-FPT project. This project evaluated if paper-based worksheets helped farmers make changes to monitor/reduce their negative environmental impact. The managers had medium shared cognition because they shared policy language/narratives about the specific goal of reducing environmental impact by farms, but their agencies focused on different aspects (see Section 4.1). The SCAs focused on public waterways and adjacent farms. DeptEnv focused on public land and adjacent farms. DeptLand helped farmers identify and implement productivity innovations, including those which reduced environmental impact. These managers had weak ties due to short meetings during projects, and due to negotiations aligning interests rather than shared obligations or power. These managers had high homophily due to having equivalent positions in their agencies and behaviours, including managing targets, but in different contexts. They had medium bridging capital because, via collaboration and links to the federal government, they collectively secured federal funding for the pre-FPT project.

Further evidence of medium shared cognition was that the managers reached the collective decision that the FPT design project should overcome the issues faced by farmers, and by staff in their agencies, who used the worksheets (see Section 4.1). Government restructuring at the start of the project meant DeptEnv and DeptLand could no longer help farmers reduce environmental impact. Further support for weak ties was that DeptEnv and DeptLand managers stopped collaborating after the restructure. This resulted in no meetings (weak structure), and weak shared cognition due to having only the same general policy language/ narrative. SpatialCo was contracted to run the FPT project. There was medium bridging capital among managers because SpatialCo offered IS-based spatial technology expertise, and DeptEnv provided project ownership and funding. SpatialCo and SCA managers had high 
structure because all had relationships in meetings. They had medium shared cognition due to common language/narratives about IS-based spatial technology, and to SpatialCo's work on similar past projects. SpatialCo and SCA managers had medium weak ties due to the SCAs' contractual power over many months. Homophily was not affected due to all managers having similar management roles and practices, but in different contexts.

The high structure and medium shared cognition among the SCA and DeptLand managers during the pre-FPT project led to DairyCo joining the second FPT evaluation during the development stage. DairyCo and DeptLand managers had weak ties during a project to help dairy farmers reduce costs and increase productivity, which led to a spreadsheet-based model to reduce fertiliser use. The managers had medium shared cognition due to similar narratives about farm productivity, but DairyCo manager narratives included farmers reducing environmental impact. DeptLand managers suggested that DairyCo managers should contact SCA managers to ask if the model could be embedded in the FPT.

DairyCo and SCA managers had medium shared cognition due to similar narratives on reducing farmers' environmental impact, but DairyCo managers were driven by productivity and global market issues. The managers had medium homophily due to similar management level positions and behaviours in different contexts. DairyCo and SCA managers did not have relationships before the FPT project (i.e. no structure and ties). DeptLand managers contributed high bridging capital, which SCA managers needed so they could run FPT evaluation 2 during the development stage, in the form of bringing in DairyCo and its resources such as field officers and funding:

We invested a little bit of money to try and improve [the FPT], or give it extra functions that we thought were going to be useful, and we then provided, sort of, on-the-ground support [i.e. field officers] through pilot programmes to work with our [farmers] [DairyCoManager/interview]

In summary, the findings suggest that manager relationships can bring in managers from new organisations that are needed for IS design (i.e. new high structure and bridging capital), even with weak ties, if there was medium shared cognition and homophily among the original managers during pre-IS and/or IS design stages.

\subsection{Enlister relationships: manager relationships with recruiters}

We found that SCA managers had difficulty enlisting SCA field officers to act as recruiters. Managers had enlister relationships with employed field officers (high structure), but field officer involvement was voluntarily due to limited funding to pay for this work on top of their normal roles. This meant SCA managers had no power over field officers, and that field officers could leave the project, even after starting. A factor contributing to optional involvement was high SCA field officer turnover (i.e. weak ties). SCA managers relied on high ties and shared cognition to enlist field officers. Their high ties had developed over many projects due to shared obligations to reduce farmer impact on waterways. High shared cognition occurred because the field officers' interests aligned with SCA manager policy targets. They had medium homophily due to linked practices/behaviours, where managers worked toward policy targets and field officers supported this through their fieldwork.

Similar enlister relationship attributes applied to DeptLand managers and field officers. For example, DeptLand managers and field officers could have weak to medium ties depending on staff turnover. There were high ties with field officers because both focused on productivity, 
rather than environmental impact, in their employment. There was high shared obligation due to common language, narratives and interests, and medium homophily due to their linked work practices centred around improving farm productivity. Similar levels for each attribute applied to DairyCo managers and field officers along the same lines.

In summary, the findings suggest that enlister relationships, among managers and recruiters, have high structure. Managers can enlist recruiters into IS design, if participation is voluntary, so long as ties and shared cognition are high, and there is medium homophily. Enlister relationships can then lead to recruiter relationships, which are discussed next.

\subsection{Recruiter relationships: recruiter relationships with SME personnel}

The next sections explain that recruiters in recruiter relationships can include people in managerial roles in the FPT project (Section 5.3.1), not just field officers (Section 5.3.2).

\subsubsection{Project-Manager-SCA1 relationships with three farmers}

The findings suggested the relationship between Project-Manager-SCA1 and three farmers, who committed to be on the FPT reference group, were instances of recruiter relationships between a recruiter and SME personnel. The three farmers were proactively exploring ways to improve farming practices, and were perceived as leading farmers:

So we had three farmers [in the reference group] who were leading farmers, who previously had been involved in things like precision agriculture, farm mapping. [Project-ManagerSCA1/interview]

Project-Manager-SCA1 had medium shared cognition with the three farmers due to shared language about technology and shared values on using technology to reduce environmental impact, but no shared farming language because Project-Manager-SCA1 was not a farmer. Project-Manager-SCA1 had direct collaborative relations with various stakeholders working on environmental impact and mapping technology. He had high structure with the farmers, because over many years he had worked in related projects, and met and worked with the farmers via his wide social network. Project-Manager-SCA1 had weak homophily with these farmers because, although they had collaborated previously, his agency role and behaviour was quite different to the farmers who ran rural properties. He had medium ties with these farmers due to years of collaboration on projects, through which they developed trust and reciprocity. Reciprocity was highlighted by Project-Manager-SCA1 enticing the farmers with medium bridging capital, made possible by his network. For example, Project-Manager-SCA1 organised study trips to universities and farming businesses, paid for the farmers to attend agronomy conferences, and invited the farmers as speakers to share and discuss their experiences and views at conferences. We were not privy to the farmers' views, but our interviews with other stakeholders confirmed that Project-Manager-SCA1 was considered a leader in the broader network. The farmers were part of this network, so it is plausible the farmers might also have seen him as a leader regarding environmental farming technology.

In summary, the findings imply managers can be recruiters. The findings also suggest that recruiter relationships can overcome weak homophily and lead to recruiting SME personnel into reference groups for all IS design stages, so long as managers have medium shared cognition, ties and bridging capital, and high structure with these SME personnel. 


\subsubsection{Field officer relationships with SME farmers}

Table 7 summarises the attributes between SCA, DeptLand and DairyCo field officers, and farmers or SME personnel, in recruiter relationships. The table shows that, outside the FPT project, the SCA and DeptLand field officers had high structure with farmers via farmer associations, and that ties and shared cognition ranged from weak to medium. Field officers offered medium bridging capital, which farmers valued to varying degrees depending on how they favoured environmental improvements versus productivity goals. Field officers offered expertise about farm initiatives and projects to attract government funding.

\begin{tabular}{|c|c|c|c|}
\hline & SCA field officers (FOs) & DeptLand FOs & DairyCo FOs \\
\hline \multicolumn{4}{|c|}{ Attributes of relationship type 1} \\
\hline Structure & $\begin{array}{l}\text { High: FOs had direct links to } \\
\text { all farmers in Environment } \\
\text { Associations in their region; } \\
\text { less outside the associations. }\end{array}$ & $\begin{array}{l}\text { High: FOs had direct links } \\
\text { only to farmers (in } \\
\text { associations) focused on } \\
\text { productivity/innovation. }\end{array}$ & $\begin{array}{l}\text { High; FOs had direct links } \\
\text { to all farmers supplying to } \\
\text { the DairyCo cooperative. }\end{array}$ \\
\hline Ties & $\begin{array}{l}\text { Weak to medium based on } \\
\text { years in the role, affected by } \\
\text { high FO turnover. FPT/FOs } \\
\text { facilitated farmer control/ } \\
\text { access to spatial maps, and } \\
\text { project/funding access linked } \\
\text { to SCA needs (reciprocity). }\end{array}$ & $\begin{array}{l}\text { Weak to medium based on } \\
\text { role duration, affected by } \\
\text { high FO turnover. FOs: } \\
\text { impeded farmer access to } \\
\text { spatial maps; facilitated } \\
\text { productivity projects/ } \\
\text { funding (reciprocity). }\end{array}$ & $\begin{array}{l}\text { High; employed to help } \\
\text { farmers comply with food } \\
\text { regulations, reduce impact } \\
\text { on environment (optional), } \\
\text { boost yields (duration, } \\
\text { reciprocity, trust, shared } \\
\text { obligation). }\end{array}$ \\
\hline $\begin{array}{l}\text { Shared } \\
\text { cognition }\end{array}$ & $\begin{array}{l}\text { Weak to medium based on if } \\
\text { FOs grew up on a farm. Farm } \\
\text { diversity and farmer views of } \\
\text { FO academic degrees affected } \\
\text { shared cognition. FOs targeted } \\
\text { farmers reducing their } \\
\text { environmental impact. }\end{array}$ & $\begin{array}{l}\text { Weak to medium based on if } \\
\text { FOs grew up on a farm. } \\
\text { Shared cognition was hard } \\
\text { due to farm diversity. } \\
\text { Farmers focused on } \\
\text { productivity and innovation } \\
\text { were targeted. }\end{array}$ & $\begin{array}{l}\text { Medium due to greater } \\
\text { farmer homogeneity (i.e. } \\
\text { dairy only). Not all } \\
\text { farmers aimed to reduce } \\
\text { their environmental } \\
\text { impact, which FOs tried to } \\
\text { encourage. }\end{array}$ \\
\hline Homophily & $\begin{array}{l}\text { Weak; FOs helped with } \\
\text { projects, but behaviour/ work } \\
\text { differed to farmers. }\end{array}$ & $\begin{array}{l}\text { Weak; FOs helped with } \\
\text { projects, but behaviour/ work } \\
\text { differed to farmers. }\end{array}$ & $\begin{array}{l}\text { Medium; FOs helped with } \\
\text { many practices, but did no } \\
\text { farming work. }\end{array}$ \\
\hline $\begin{array}{l}\text { Bridging } \\
\text { capital }\end{array}$ & $\begin{array}{l}\text { Medium; FOs aided access to } \\
\text { SCA funds, expertise on } \\
\text { reducing ecological impact. }\end{array}$ & $\begin{array}{l}\text { Medium; FOs aided access to } \\
\text { DeptLand funds, } \\
\text { productivity expertise. }\end{array}$ & $\begin{array}{l}\text { Medium; FOs aided access } \\
\text { to DairyCo funds, dairy- } \\
\text { related expertise. }\end{array}$ \\
\hline \multicolumn{4}{|c|}{ FPT design stages } \\
\hline $\begin{array}{l}\text { Nature of } \\
\text { influence }\end{array}$ & $\begin{array}{l}\text { Recruited farmers during: } \\
\text { - the pre-FPT design stage } \\
\text { - the concept stage } \\
\text { - the FPT evaluation } 1 \text { of the } \\
\text { development stage. }\end{array}$ & $\begin{array}{l}\text { Discouraged farmers from } \\
\text { being recruited during: } \\
\text { - the FPT evaluation } 1 \text { of } \\
\text { the development stage. }\end{array}$ & $\begin{array}{l}\text { Recruited farmers during: } \\
\text { - } \quad \text { the FPT evaluation } 2 \\
\text { of the development } \\
\text { stage. }\end{array}$ \\
\hline
\end{tabular}

Table 7: Field officer relationships with farmers

Table 7 implies that nuanced challenges affected the degree to which each type of field officer was able to recruit farmers into the FPT project. This included that DeptLand field officers impeded the ability of SCA field officers to recruit some farmers, especially during FPT evaluation 1 of the development stage, after DeptLand left the consortium (see Table 6 and Section 5.1). These nuances and tensions are elaborated on next.

The first nuance for SCA and DeptLand field officers, noted in Section 4.1, was dealing with the diversity of farm size, farm type (e.g. livestock/crop, hobby versus commercial), and farmer IS skills that ranged from basic to proficient. The diversity meant it was difficult for a single 
field officer to have medium or higher shared cognition and homophily with every farmer. This constrained the ability of SCA field officers to satisfy the goal of involving many diverse farmers in the FPT development stage (evaluation 1). DairyCo field officers had fewer issues because they were employed (high ties) specifically to support an homogeneous type of farm with a common language and similar business goals (medium shared cognition).

A second nuance was that our analysis of secondary sources such as government reports and biographies implied that field officers varied on farming background such as being on farms as children, and on the university education that field officers typically needed to have such as agricultural, environmental and natural sciences. This has implications for field officer relationships with farmers, which would then vary depending on the value each farmer placed on the traits of the particular field officers with whom they might engage. This issue potentially weakens shared cognition and strength of ties, and thus possibly the field officers' ability to convince farmers to participate during the FPT design stages. Since we did not interview farmers, we cannot verify if farmers considered this when deciding to join the FPT project. Nonetheless, the fact the SCA field officers were able to recruit farmers meant these farmers, at the very least, likely respected the field officers' background/experience.

A tension between SCA and DeptLand field officers during FPT evaluation 1 (development stage) emerged due to four interrelated nuances and complications:

- Section 4.1 noted that DeptEnv, DeptLand and the SCAs had their own, often different, field officers working with farmers to implement changes aligned with each government agency's portfolio. A single farmer could thus be approached and supported by a field officer from one or more of these agencies.

- $\quad$ The farmers varied in how they prioritised reducing environmental impact with other concerns including productivity and their work practices. This created tensions regarding which field officer type each farmer would consider credible.

- $\quad$ FPT evaluation 1 required four months of involvement (see Table 4), which made it more challenging for SCA field officers to convince farmers to join the FPT project.

- $\quad$ The manager relationship issue of DeptLand leaving the project meant DeptLand field officers used another software mapping tool when visiting farmers, and did not give farmers access and sent printed maps to farmers, instead of promoting the FPT.

Project-Manager-SCA1 believed the FPT threatened DeptLand field officer power, and thus the field officers used their mapping tool and withheld FPT details to maintain this power:

So we were very interested in the power relationship between, if you are the [DeptLand field] officer and I'm the farmer, and you have all the information and I get to see it, but I don't get to... I am not able to interact with it after you go, then the power relationship is unequal. And we were keen to provide more power to the farmers so they could access the information themselves... But some [DeptLand field officers] found that they had to give up some of their power through this [FPT project], so they were less enthusiastic about it. [Project-ManagerSCA1/interview]

DeptLand field officers were thus able to discourage farmers from joining FPT evaluation 1, especially if they had greater shared cognition, ties and/or bridging capital compared to what 
farmers had with SCA field officers. For instance, if farmers felt productivity outweighed reducing ecological impact, or DeptLand field officers convinced them, then SCA field officers would have had difficulty enticing such farmers to take part in FPT evaluation 1.

SCA field officers thus relied on relations with farmers from local Environment Associations (high structure) that they established over time before and during the FPT project (medium ties), and farmers who valued SCA funds and expertise (medium bridging capital). These enduring relationships were more likely to give farmers confidence that SCA field officers would support farmers during the four month FPT evaluation 1, despite weak homophily.

DairyCo field officers had fewer issues recruiting farmers during FPT evaluation 2, which lasted eighteen months (see Table 4), for two reasons adding to the above points. First, dairy farmers were less likely to be approached by other field officers, because DairyCo provided dedicated field officers who covered all dairy work (medium homophily). Second, DairyCo field officers' success in recruiting farmers to the evaluation depended on the farmer's degree of interest in environmental issues, and on their business goals (high ties). The field officers focused on using the FPT to create farm maps if farmers were not interested in the FPT's environmental management capabilities. SCA field officers, by contrast, supported farmers of different types (e.g. crops) and targeted environmental issues as required by their agency.

In summary, the findings suggest that recruiter relationships, among recruiters and SME personnel, may lead to SME personnel being recruited into IS design if there is medium shared cognition, ties and bridging capital, and high structure. However, this depends on whether other recruiter relationships, with the same or better relationship attributes, are able to impede the recruitment of the same SME personnel, because these recruiters recruit SME personnel into alternative projects, for instance, to maintain their power over SMEs.

\section{Discussion}

We argued that limited research has examined the relationships among stakeholders that can lead to SME personnel being recruited into IS design. This research is needed for two reasons. First, SME involvement in IS design is an important contributor to later IS adoption by SMEs in developed (Lynch \& Gregor 2004) and developing countries (Doerflinger \& Dearden 2013). Second, recruiting SME personnel is not trivial because they can be time poor (Cragg et al. 2011) and, in developing countries, may not trust recruiters (Oduor et al. 2018). The limited research summarised in Section 2 implied there are three relationship types. Recruiter relationships are between recruiters and SME personnel, where recruiters use existing/new relationships to recruit SME personnel. Enlister relationships involve organisational managers using existing/new relationships to enlist recruiters, who will enact recruiter relationships. Manager relationships involve managers from organisations using existing/new relationships with managers of other organisations to facilitate enlister and recruiter relationships. The limited research meant it was unclear what attributes of the three relationship types can explain how SME personnel are recruited into IS design, and what theoretical concepts underpin the attributes. We presented the findings of an in-depth revelatory case study about the design of an inter-organisational, web-based spatial IS called the Farm Planning Tool (FPT). The FPT collected information from diverse SME farmers about the ecological impact of their farms, which was used by State Catchment Authorities (SCAs) and a dairy organisation (DairyCo). SCA and DiaryCo managers collaborated, via manager relationships, and enlisted their field officers, via enlister relationships, who in turn recruited SME farmers 
via recruiter relationships. Our hermeneutic approach to data analysis enabled us to address the question: What attributes of relationships among managers, field officers and farmers help explain how farmers were recruited during FPT design? In addressing this research question, the paper makes the following contributions.

First, Boonstra's (2009) framework conceptualises IS stakeholders using stakeholder theory, IS project stages, and stakeholder participation as degrees of involvement including having an 'influence' on IS design. We focused on manager and field officer stakeholders who recruited farmers, or users, into the concept and development stages of an IS project. These stakeholders wanted farmers to 'influence' the FPT design. This paper extends Boonstra's framework by providing evidence about the importance of adding our three relationship types to the framework to facilitate examination of how stakeholders can recruit farmers, as users, during the concept and development stages of an IS project. We also extended the framework by finding empirical evidence that the social capital concepts, which were summarised in Table 1 and Table 5, can help theorise the attributes of the three relationship types. We shows that the relationship types and social capital concepts can help explain how farmers can be recruited, because we were able to use these to analyse the strength (weak, medium and high) and combination of the concepts to explain the findings.

Second, we used social capital in the context of the relationship types that lead SME farmers to be recruited into IS design, which makes a contribution to our discipline for two reasons:

1. Social capital concepts are used mainly to explore SME perspectives of knowledge sharing and value creation among SMEs using existing IS (e.g. Mason et al. 2008a; Mason et al. 2008b). This paper's contribution is to show these concepts can explain manager and recruiter perspectives (who are not SME personnel) about recruiting farmers when designing a new IS, not an existing IS.

2. IS design studies use social capital concepts to explore design teams interactions (e.g. Chang et al. 2011; Chou \& He 2011; Kotlarsky \& Oshri 2005; Paavola \& Hallikainen 2016; Robert et al. 2008), and snowball techniques to recruit users in large-scale intra-organisational projects (e.g. Lim \& Finkelstein 2012; van Limburg et al. 2015). That is, these studies explore relationships among stakeholders in a single organisation. Even studies involving SMEs have used social capital concepts to examine relationships among consultants and SME owner-managers when designing a website for a single SME (e.g. Burgess et al. 2012). A contribution of this paper is showing these concepts can also make sense of relationships between IS project members and users during the design of an inter-organisational IS.

Third, this study highlights the interrelatedness of the three relationship types when it comes to recruiting SME personnel into IS design, and the need to examine them together in detail to understand the complexity. For example, the findings showed that the tensions in manager relationships among different organisations, including the SCAs and DeptLand, led DeptLand field officers to promote an alternative IS to farmers via recruiter relationships, and to discourage farmers from being recruited into the FPT design project. Our insight into the interrelatedness of the relationship types makes a contribution because the few similar studies in this area only report on or clarify aspects of manager relationships (e.g. Fisher \& Craig 2005; Salmivalli et al. 2008; Zewge et al. 2015), or enlister and recruiter relationships (e.g. Oduor et al. 2018). The studies offering some insight into all three relationship types (e.g. Breuer et al. 2008; Doerflinger \& Dearden 2013) are consistent with our findings, because the superficial 
insights from these studies imply all three relationship types are relevant. But our study extends this work by exploring the attributes and complex interrelatedness of the three relationship types in detail. Specifically, our theorising makes sense of how the relationship types evolve and are interconnected.

Fourth, our study confirms the findings of the few studies which offer insights into the relationship attributes that can enable the recruitment of SME personnel into IS design. We extend this prior work by positing that social capital concepts can underpin these attributes. With recruiter relationships, for example, we found that field officer and farmer relationships prior to the FPT project aided recruitment, which is consistent with Oduor et al. (2018) and Jakku and Thorburn (2010). Such prior relationships can be theorised using the social capital concepts of: structure, including the extent/number of connections among recruiters and SME personnel; and ties including the duration of a relationship and the trust that develops over time. Our finding that field officer relationships with farmers were supported by bridging capital, including helping farmers access grants, was similar to Oduor et al. (2018). Oduor et al. report that goodwill was created with an Ethiopian community of farmers when the researchers left water sensor technology that was used in a past project with the community, which helped recruit farmers during a later IS design project. The finding in our study, that greater homophily among field officers and farmers can help explain recruitment, is consistent with Breuer et al. (2008) and Oduor et al. (2018) who imply that common knowledge/experience among researchers and farmers helped to recruit farmers. Finally, our finding that shared cognition, or common language/values, helped field officers recruit farmers is consistent with Oduor et al. (2018), who implied that researchers' common language and knowledge of local Ethiopian norms helped the researchers recruit farmers. Overall, these examples suggest our approach to theorising relationship attributes may apply to other contexts, including recruiting farmers into IS design in Canada (Breuer et al. 2008) and in developing countries such as Ethiopia (Oduor et al. 2018).

These examples suggest that the three relationship types, and their associated attributes, have potential to extend the IS design methodology developed by Doerflinger and Dearden (2013) for use in developing countries. The methodology highlights the importance of negotiations and contracts, and building strong relationships between researchers, a change manager and managers of local partners (i.e. manager relationships). This is needed before local farmers and other stakeholders will participate in IS design. Our findings, together with Oduor et al. (2018), suggest that social capital concepts may be a useful extension of this methodology. For example, the concepts posit that strong ties and higher degrees of homophily need to be developed between, for instance, the change manager and local partner managers. These concepts may also explain why the Doerflinger and Dearden methodology emphasises the critical role played by local partner and local contact organisations when it comes to recruiting SME personnel in developing countries. For example, managers of local contact organisations would have access to a network of volunteers (structure) with established voluntary aid collaborations (ties) that enable the managers to enlist volunteers (i.e. enlister relationships). The managers would need to convince volunteers that the IS design project is consistent with the values of the volunteers (shared cognition). Doerflinger and Dearden imply that the relationships among volunteers and local African communities (i.e. recruiter relationships) enable volunteers to recruit and execute IS design activities. The social capital concepts may help theorise why. Volunteers with pre-existing relationships with SME personnel (structure) from prior volunteer work (strong ties), have common norms (shared cognition) and access to 
aid (bridging capital), which enables volunteers to recruit local community members, including SME personnel.

\section{Conclusion}

This next section concludes the paper by summarising the practical contributions of this study, the limitations of this study, and the future research agenda.

\subsection{Practical implications}

This is a detailed empirical study, and practitioners may benefit from our extensions to Boonstra's (2009) IS stakeholder management framework, and to Doerflinger and Dearden's (2013) IS design methodology for developing countries. Practical implications of these extensions imply that IS design teams need to facilitate the effective interplay of the three relationship types, and pursue favourable relationship attributes, to increase the likelihood that SME personnel will be recruited into the concept and development stages of IS design. Our empirical study highlights that this is not trivial, because other stakeholders may use the three relationship types, and associated attributes, to undermine the recruitment of SME personnel. This means that IS design teams must identify the manager, enlister and recruiter relationships which may be threats, and which may mean SME personnel are targeted by recruiters who promote a competing project. Stakeholders must devise strategies that exploit the three relationship types to counteract such threats. Our findings indicate that developing new relationships, or capitalising on existing relationships, with higher degrees of structure or access to SME personnel, and ties, shared cognition and homophily between recruiters and SME personnel, may help with recruiting SME personnel during IS design projects.

\subsection{Limitations}

The study reported in this paper has limitations including: 1) being a single case study which, we emphasise, is not intended to demonstrate best practice in how relationship types and associated attributes can help IS design teams recruit SME personnel ; 2) identifying what relational types and attributes were used and how, but not why they were used; 3) not reporting on SME personnel experiences; and 4) examining manager and recruiter recollections of a historical IS design project rather than studying a project as it unfolded. Nonetheless, the paper is among the first in-depth studies of: the three relationship types and attributes that explain how SME personnel were recruited into an IS design project; and the theoretical concepts which scholars can use to frame much needed research in this area.

\subsection{Future research agenda}

We anticipate our proposed extensions to Boonstra's IS stakeholder management framework and Doerflinger and Dearden's IS design methodology for developing countries can underpin a future research agenda by IS scholars. For example, case studies and action research can examine IS design projects in developed and developing countries where SME personnel involvement is desired, and apply the three relationship types and associated attributes based on social capital to explore why SME personnel were or were not recruited. Future research can determine if the three levels we have used for each relationship attribute in Table 5, and the descriptions of each, are appropriate for other IS design contexts. Scholars can conduct action research studies to identify and examine effective strategies, informed by our extensions to the above framework and methodology, that can improve SME personnel recruitment during IS design. Finally, scholars could integrate our work with other theories to explore 
nuances further. For example, Tatnall and Burgess (2009) imply that actor network theory could theorise the negotiations in manager relationships. Activity theory could extend our understanding of homophily, ties and shared cognition in all three relationship types, because this theory focuses on the sources of tension in relationships among actors involved in day-today practices (Karanasios 2018).

\section{References}

ABS (2012). Australian social trends, Dec 2012: Australian farming and farmers. Catalogue No. 4102.0, Australian Bureau of Statistics, Canberra. Retrieved from http://www.abs.gov.au/AUSSTATS/abs@.nsf/Lookup/4102.0Main+Features10Dec+2012

ABS (2015). Counts of Australian businesses, including entries and exits, Jun 2010 to Jun 2014. Catalogue No. 8165.0, Australian Bureau of Statistics, Canberra. Retrieved from http://www.abs.gov.au/ausstats/abs@.nsf/mf/8165.0

Bødker, M., Gimpel, G., \& Hedman, J. (2014). Time-out/time-in: the dynamics of everyday experiential computing devices. Information Systems Journal, 24(2), 143-166. https://doi.org/10.1111/isj.12002

Boonstra, A. (2009). Identifying and managing stakeholders in enterprise information system projects. Intemational Journal of Enterprise Infomation Systems, 5(4), 1-16. https://doi.org/10.4018/jeis.2009090201

Breuer, N.E., Cabrera, V.E., Ingram, K.T., Broad, K., \& Hildebrand, P.E. (2008). AgClimate: a case study in participatory decision support system development. Climatic Change, 87, 385-403. https://doi.org/10.1007/s10584-007-9323-7

Breuer, N.E., Fraisse, C.W., \& Hildebrand, P.E. (2009). Molding the pipeline into a loop: the participatory process of developing AgroClimate, a decision support system for climate risk reduction in agriculture. Journal of Service Climatology, 3(1), 1-12.

Burgess, S., Bingley, S., \& Hunter, M.G. (2012). Involvement in small community based organisations' websites. Journal of Information, Information Technology, and Organizations, 6, 63-80. https://doi.org/10.28945/1696

Cabrera, V.E., Breuer, N.E., \& Hildebrand, P.E. (2008). Participatory modeling in dairy farm systems: a method for building consensual environmental sustainability using seasonal climate forecasts. Climatic Change, 89(3-4), 395-409. https://doi.org/10.1007/s10584-0079371-z

Cerf, M., Jeuffroy, M.-H., Prost, L., \& Meynard, J.-M. (2012). Participatory design of agricultural decision support tools: taking account of the use situations. Agronomy for Sustainable Development, 32(4), 899-910. https://doi.org/10.1007/s13593-012-0091-z

Chang, K.-C., Wong, J.-H., Li, Y., Lin, Y.-C., \& Chen, H.-G. (2011). External social capital and information systems development team flexibility. Information and Software Technology, 53, 592-600. https://doi.org/10.1016/j.infsof.2011.01.007

Chou, S.-W., \& He, M.-Y. (2011). The factors that affect the performance of open source software development - the perspective of social capital and expertise integration. Information Systems Journal, 21(2), 195-219. https://doi.org/10.1111/j.13652575.2009.00347.x 
Churi, A.J., Mlozi, M.R.S., Mahoo, H., Tumbo, S.D., \& Casmir, R. (2013). A decision support system for enhancing crop productivity of smallholder farmers in semi-arid agriculture. International Journal of Information and Communication Technology Research, 3(8), 238-248.

Cragg, P.B., Caldeira, M.M., \& Ward, J.M. (2011). Organizational information systems competences in small and medium-sized enterprises. Information $\mathcal{E}$ Management, 48(8), 353-363. https://doi.org/10.1016/j.im.2011.08.003

Dans, E., \& Freire, J. (2002). IT as an agent of social change: Lonxanet and the case of the Galician artisanal fisheries. 23rd International Conference on Information Systems, 15-18 December, Barcelona, Spain.

Doerflinger, J., \& Dearden, A. (2013). Evolving a software development methodology for commercial ICTD projects. Information Technologies E International Development, 9(3), 4360 .

Eastwood, C.R., Dela Rue, B.T., \& Gray, D.I. (2017). Using a 'network of practice' approach to match grazing decision-support system design with farmer practice. Animal Production Science, 57(7), 1536-1542. https://doi.org/10.1071/AN16465

Fisher, J., \& Craig, A. (2005). Developing business community portals for SMEs - issues of design, development and sustainability. Electronic Markets, 15(2), 136-145. https://doi.org/10.1080/10196780500083811

Gichamba, A., \& Lukandu, I.A. (2012). A Model for designing m-agriculture applications for dairy farming. The African Journal of Information Systems, 4(4), 120-136.

Granovetter, M.S. (1973). The strength of weak ties. American Journal of Sociology, 78(6), 13601380. https://doi.org/10.1086/225469

Harwood, S.A. (2011). The domestication of online technologies by smaller businesses and the 'busy day'. Information and Organization, 21(2), 84-106. https://doi.org/10.1016/j.infoandorg.2011.03.002

Heckathorn, D.D. (2011). Comment: snowball versus respondent-driven sampling. Sociological Methodology, 41(1), 355-366. https://doi.org/10.1111/j.1467-9531.2011.01244.x

Heeks, R. (2008). ICT4D 2.0: the next phase of applying ICT for international development. Computer, 41(6), 26-33. https://doi.org/10.1109/MC.2008.192

Holgersson, J. (2014). User participation in public e-service development: guidelines for including external users. PhD thesis, University of Skovde.

Huang, G.H., Sun, W., Nie, X.-H., Qin, X.-S., \& Zhang, X.-D. (2010). Development of a decisionsupport system for rural eco-environmental management in Yongxin County, Jiangxi Province, China. Environmental Modelling \& Software, 25(1), 24-42. https://doi.org/10.1016/j.envsoft.2009.07.010

Islam, M.S., \& Grönlund, Å. (2007). Agriculture market information e-service in Bangladesh: a stakeholder-oriented case analysis. In M.A. Wimmer, H.J. Scholl and Å. Grönlund (Eds.), Electronic Government (vol. 10.1007/978-3-540-74444-3_15, pp. 167-178). Berlin, Heidelberg: Springer. https://doi.org/10.1007/978-3-540-74444-3_15 
Jakku, E., \& Thorburn, P.J. (2010). A conceptual framework for guiding the participatory development of agricultural decision support systems. Agricultural Systems, 103(9), 675682. https://doi.org/10.1016/j.agsy.2010.08.007

Karanasios, S.S. (2018). Toward a unified view of technology and activity: the contribution of activity theory to information systems research. Information Technology $\mathcal{E}$ People, 31(1), 134-155. https://doi.org/10.1108/ITP-04-2016-0074

Klein, H.K., \& Myers, M.D. (1999). A set of principles for conducting and evaluating interpretive field studies in information systems. MIS Quarterly, 23(1), 67-93.

Kotlarsky, J., \& Oshri, I. (2005). Social ties, knowledge sharing and successful collaboration in globally distributed system development projects. European Journal of Information Systems, 14, 37-48. https://doi.org/10.1057/palgrave.ejis.3000520

Kvale, S. (2007). Doing Interviews. London: SAGE Publications.

Lim, S.L., \& Finkelstein, A. (2012). StakeRare: using social networks and collaborative filtering for large-scale requirements elicitation. IEEE Transactions on Software Engineering, 38(3), 707-735. https://doi.org/10.1109/TSE.2011.36

Lynch, T., \& Gregor, S. (2004). User participation in decision support systems development: influencing system outcomes. European Journal of Information Systems, 13(4), 286-301. https://doi.org/10.1057/palgrave.ejis.3000512

Lyytinen, K., \& Damsgaard, J. (2011). Inter-organizational information systems adoption - a configuration analysis approach. European Journal of Information Systems, 20(5), 496-509. https://doi.org/10.1057/ejis.2010.71

Mason, C., Castleman, T., \& Parker, C.M. (2008a). Communities of enterprise: developing regional SMEs in the knowledge economy. Journal of Enterprise Information Management, 21(6), 571-584. https://doi.org/10.1108/17410390810911186

Mason, C., Castleman, T., \& Parker, C.M. (2008b). Socio-technical factors influencing channel use for knowledge-sharing in regional SME networks. International Journal of Knowledge Management Studies, 2(3), 303-319. https://doi.org/10.1504/IJENM.2008.018794

McPherson, M., Smith-Lovin, L., \& Cook, J.M. (2001). Birds of a feather: homophily in social networks. Annual Review of Sociology, 27, 415-444. https://doi.org/10.1146/annurev.soc.27.1.415

Merz, C., De Louw, R., \& Ullrich, N. (2007). Collaborative working environments for enterprise incubation - The Sekhukhune Rural Living Lab. 2nd IST-Africa Conference E Exhibition, 9-11 May, Maputo, Mozambique.

Miah, S.J., Kerr, D., \& von Hellens, L. (2014). A collective artefact design of decision support systems: design science research perspective. Information Technology \& People, 27(3), 259279. https://doi.org/10.1108/ITP-04-2012-0041

Nahapiet, J., \& Ghoshal, S. (1998). Social capital, intellectual capital, and the organizational advantage. Academy of Management Review, 23(2), 242-266. https://doi.org/10.5465/amr.1998.533225

Ndou, V., Del Vecchio, P., \& Schina, L. (2011). Designing digital marketplaces for competitiveness of SMEs in developing countries. In M. Obaidat and J. Filipe (Eds.), e- 
Business and Telecommunications (vol. 10.1007/978-3-642-20077-9_6, pp. 82-93). Milan, Italy: Springer Berlin Heidelberg. https://doi.org/10.1007/978-3-642-20077-9_6

Nolan, T., Brizland, R., \& Macaulay, L.A. (2007). Individual trust and development of online business communities. Information Technology \& People, 20(1), 53-71. https://doi.org/10.1108/09593840710730554

Noor, N.L.M., \& Nordin, A. (2012). Requirements elicitation for the technology conception of a community information system for the indigenous microenterprise: a contextual multianalysis approach on business and community requirements of batik making. Electronic Journal of Information Systems Evaluation, 15(1), 102-115.

Oduor, E., Waweru, P., Lenchner, J., \& Neustaedter, C. (2018). Practices and technology needs of a network of farmers in Tharaka Nithi, Kenya. 35th ACM Conference on Human Factors in Computing Systems, 21-26 October, Montreal, Canada. https://doi.org/10.1145/3173574.3173613

Paavola, R., \& Hallikainen, P. (2016). Antecedents for successful collaboration in requirements engineering. VINE Journal of Information and Knowledge Management Systems, 46(3), 353370. https://doi.org/10.1108/VJIKMS-03-2016-0013

Parker, C., \& Sinclair, M. (2001). User-centred design does make a difference. The case of decision support systems in crop production. Behaviour \& Information Technology, 20(6), 449-460. https://doi.org/10.1080/01449290110089570

Parker, C.M., Burgess, S., \& Al-Qirim, N.A.Y. (2015). A review of studies on information systems and SMEs in high ranked IS journals (2000-2014). Australasian Journal of Information Systems, 19, S153-S173. https://doi.org/10.3127/ajis.v19i0.1219

Parker, C.M., \& Castleman, T. (2009). Small firm eBusiness adoption: a critical analysis of theory. Journal of Enterprise Information Management, 22(1/2), 167-182. https://doi.org/10.1108/17410390910932812

Patton, M.Q. (2002). Qualitative Research and Evaluation Methods (3rd ed.). Thousand Oaks, California: SAGE Publications.

Pouloudi, N., Currie, W.L., \& Whitley, E.A. (2016). Entangled stakeholder roles and perceptions in health information systems: a longitudinal study of the U.K. NHS N3 Network. Journal of the Association for Information Systems, 17(2), 107-161.

Putnam, R.D. (2000). Bowling Alone: The Collapse and Revival of American Community. New York: Simon \& Schuster.

Robert, L.P., Dennis, A.R., Jr., \& Ahuja, M.K. (2008). Social capital and knowledge integration in digitally enabled teams. Information Systems Research, 19(3), 314-334. https://doi.org/10.1287/isre.1080.0177

Rodon, J., Pastor, J.A., Sese, F., \& Christiaanse, E. (2008). Unravelling the dynamics of IOIS implementation: an actor-network study of an IOIS in the seaport of Barcelona. Journal of Information Technology, 23(2), 97-108. https://doi.org/10.1057/palgrave.jit.2000131

Salmivalli, L.A.T., Salmela, H., \& Kestila, T. (2008). Building inter-organizational cooperative network for IT collaboration. 41st Annual Hawaii International Conference on System Sciences, 7-10 January, Waikoloa Village, Hawaii. https://doi.org/10.1109/HICSS.2008.81 
Schlichter, B.R., \& Rose, J. (2013). Trust dynamics in a large system implementation: six theoretical propositions. European Journal of Information Systems, 22(4), 455-474. https://doi.org/10.1057/ejis.2012.24

Tatnall, A., \& Burgess, S. (2009). Portals then and now: development and use of portals in Australia and Bangladesh. International Journal of Web Portals, 1(4), 21-33. https://doi.org/10.4018/jwp.2009071302

van Limburg, M., Wentzel, J., Sanderman, R., \& van Gemert-Pijnen, L. (2015). Business modeling to implement an eHealth portal for infection control: a reflection on co-creation with stakeholders. JMIR Research Protocols, 4(3). https://doi.org/10.2196/resprot.4519

Walsham, G. (1995). Interpretive case studies in IS research: nature and method. European Journal of Information Systems, 4(2), 74-81. https://doi.org/10.1057/ejis.1995.9

Winschiers-Theophilus, H., Bidwell, N.J., \& Blake, E. (2012). Community consensus: design beyond participation. Design Issues, 28(3), 89-100. https://doi.org/10.1162/DESI_a_00164

Wolcott, H.F. (1994). Transforming Qualitative Data: Description, Analysis, and Interpretation. Thousand Oaks, California: SAGE Publications.

Yin, R.K. (2014). Case Study Research: Design and Methods (5th ed.). Thousand Oaks, California: Sage Publications.

Zewge, A., Dittrich, Y., \& Bekele, R. (2014). Providing market information for Ethiopian farmers: extending participatory design. 13th Participation for Development Conference, 610 October, Windhoek, Namibia.

Zewge, A., Dittrich, Y., \& Bekele, R. (2015). Adapting participatory design to design information system with rural Ethiopian community. 12th Africon Conference in Africa, 14-17 September, Addis Ababa, Ethiopia. https://doi.org/10.1109/AFRCON.2015.7331974

Copyright: (C) 2019 Parker, Agustiono, Carr \& Saundage. This is an open-access article distributed under the terms of the Creative Commons Attribution-NonCommercial 3.0 Australia License, which permits non-commercial use, distribution, and reproduction in any medium, provided the original author and AJIS are credited. 


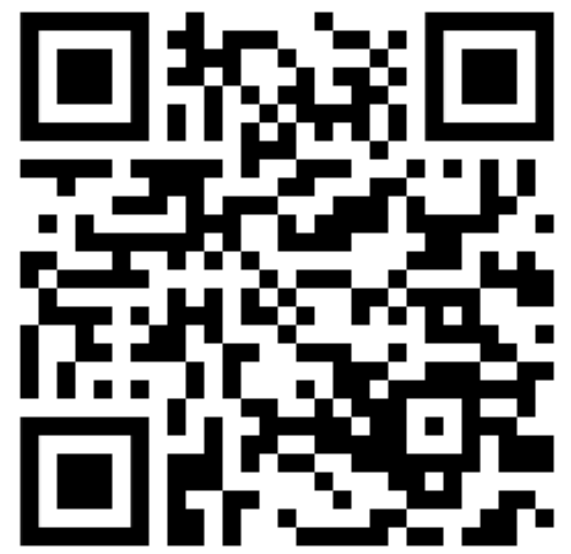

